\title{
Solar Cycle Signals in the Pacific and the Issue of Timings
}

\author{
INDRANI ROY AND JOANNA D. HAIGH \\ Department of Physics, Imperial College London, London, United Kingdom
}

(Manuscript received 17 October 2011, in final form 21 December 2011)

\begin{abstract}
The solar cycle signal in sea level pressure during 1856-2007 is analyzed. Using composites of data from January-February in solar cycle peak years the strong positive signal in the region of the Aleutian low, found by previous authors, is confirmed. It is found, however, that signals in other regions of the globe, particularly in the South Pacific, are very sensitive to the choice of reference climatology. Also investigated is the relationship between solar activity and sea surface temperatures in the tropical eastern Pacific. A marked overall association of higher solar activity with colder temperatures in the tropical Pacific that is not restricted to years of peak sunspot number is noted. The ENSO-like variation following peak years that has been suggested by other authors is not found as a consistent signal. Both the SLP and SST signals vary coherently with the solar cycle and neither evolves on an ENSO-like time scale. The solar signals are weaker during the period spanning approximately 1956-97, which may be due to masking by a stronger innate ENSO variability at that time.
\end{abstract}

\section{Introduction}

Efforts to detect a solar 11-yr cycle influence in sea surface temperatures (SSTs) have found differing signals in the tropical Pacific Ocean. Van Loon et al. (2007), van Loon and Meehl (2008), Meehl et al. (2008), and Meehl and Arblaster (2009) detected a strong La Niña-like cooling of the eastern Pacific whereas White et al. (1997), Tung and Zhou (2010), and Roy and Haigh (2010) found weak warming in the same region. The apparent disparity has been explained as due to the different methodologies used in the analyses. Van Loon et al. (2007) deduced the solar signal by taking a composite of the data corresponding to the years identified with the peaks of the solar activity cycles, and then associating the anomaly relative to a background climatology with the effects of the sun. The use by Meehl et al. (2008) of a different climatology produced similar patterns although with quantitative differences in both the signal and the apparent level of statistical significance in various regions. It has been shown by Zhou and Tung (2010) that the signal detected using the compositing method may be

\footnotetext{
Corresponding author address: Dr. Indrani Roy, College of Engineering, Mathematics and Physical Sciences, University of Exeter, Harrison Building, North Park Road, Exeter EX4 4QF, United Kingdom.

E-mail: i.roy@exeter.ac.uk
}

sensitive to the choice of details of the method. It may also be biased by a mixing of the signal with other strongly varying components such as ENSO (Roy and Haigh 2010).

Meehl et al. $(2008,2009)$ suggested that the difference between the results of van Loon et al. (2007) and those of White et al. (1997) was that the filtering of the data in the latter work produced a delay from the solar peak year and that the La Niña-like cooling had subsequently been replaced by an El Niño-like warming. White and Liu (2008) proposed a phase locking of the ENSO and solar cycles that produced a similar timing of events. Roy and Haigh (2010) pointed out that the year of peak sunspot number (SSN) in a solar cycle usually precedes the maximum of the broader decadal solar variation by at least a year. Thus, the multiple regression approach used by Tung and Zhou (2010) and Roy and Haigh (2010) presents the solar signal as corresponding more broadly to the maximum of decadal solar variations rather than particularly to the peak SSN years.

ENSO-like signals have also been produced in climate models forced with variations in solar irradiance appropriate for the solar cycle (Meehl et al. 2009). The timing of the ENSO phase relative to the solar cycle, however, varies among models: the Parallel Climate Model (PCM) simulations showed cooling that starts one year before, with warming the year following the peak SSN year, whereas experiments with the Community Climate 
a)

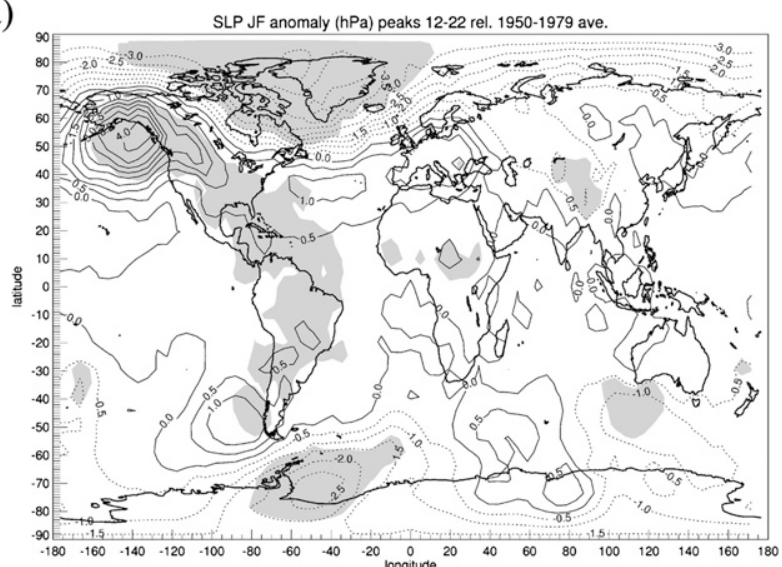

b)

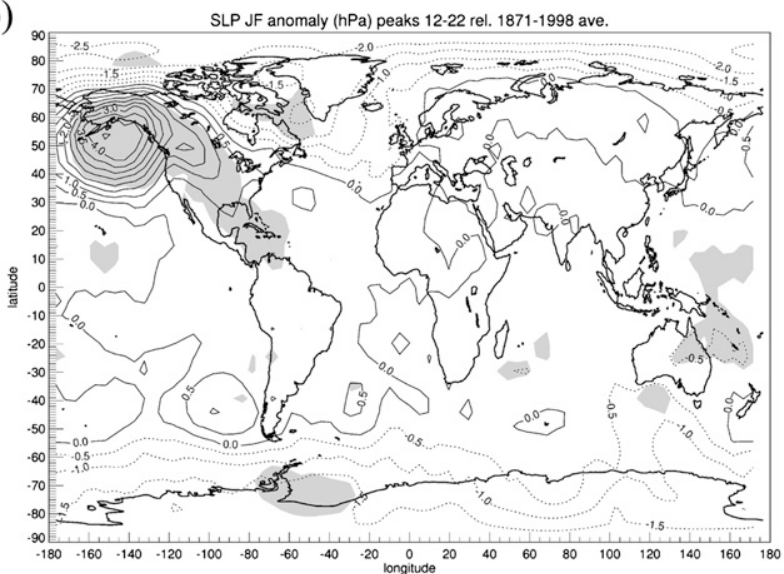

c)

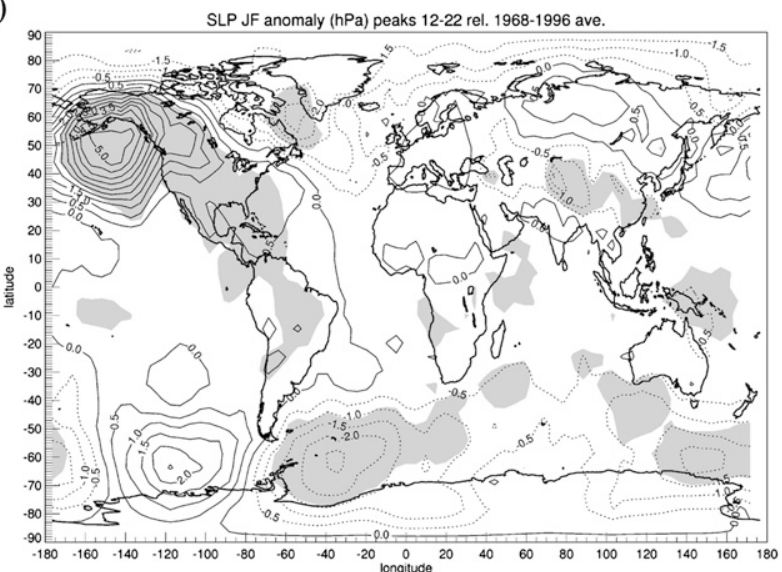

d)

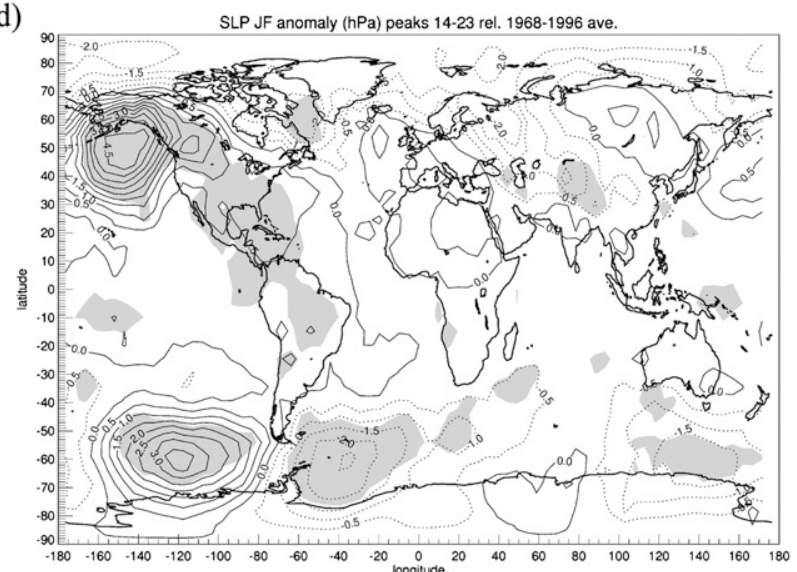

FIG. 1. Solar signal in January-February SLP (hPa) in the HadSLP2 dataset based on the method of compositing data from years of solar cycle peak sunspot number. (a) Using 11 solar cycle peak sunspot years during 1871-1989 relative to a climatology during 1950-79 [similar to van Loon et al. (2007)]. (b) As in (a), but relative to 1871-1998 [similar to Meehl et al. (2008)]. (c) As in (a), but relative to 1968-96. (d) As in (c), but with 10 solar peak years during 1905-2000 [similar to van Loon and Meehl (2011)]. Shaded regions are estimated significant at the $95 \%$ level using a $t$ test.

System Model version 3 (CCSM3) indicated warming one year before and cooling in the peak SSN year, with the cooling persisting into the following year (see Fig. 1 of Meehl et al. 2009). Neither of the model results is consistent with the observational results of van Loon and Meehl (2008), who showed maximum cooling in peak SSN years, preceded and followed by lesser cooling (and no warming). Thus, a consensus on the evolution of eastern tropical Pacific SST in relation to solar cycle remains to be established.

Solar cycle signals have also been found in sea level pressure (SLP). Compositing 11 peak solar years of January-February (JF) data, relative to the climatology [1950-79, December-February (DJF)], van Loon et al. (2007) found a very strong positive solar signal in the region of the Aleutian low (AL), with a secondary negative footprint in midlatitudes, crossing the international date line. Meehl et al. (2008), using a different reference climatology, found a similar pattern but with smaller amplitude. Van Loon and Meehl (2011) detected a strong solar signal in the southern Pacific using a climatology over a shorter and more recent period.

In this paper we look more closely at solar signals in SLP and SST in the Pacific, and at the timing of ENSO events relative to the phase of the solar cycle, to see if a consistent pattern can be identified. Motivated by the observed change in tropical mean climate since the midtwentieth century, we also investigate whether any solar cycle signal changes around this time.

\section{Solar signal using solar peak year compositing}

First, following the study of Zhou and Tung (2010), we look at the impact of the choice of reference climatology, and the choice of solar cycles, on signals in SLP deduced using the technique of compositing the data by 
(a)
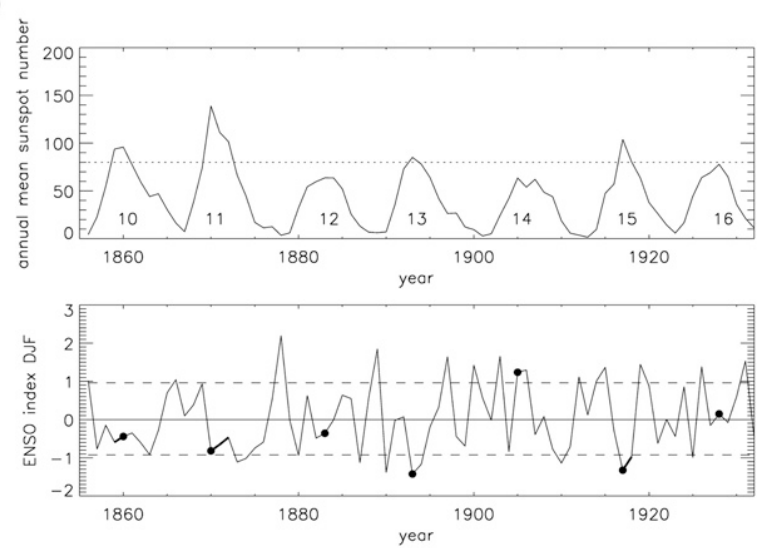

(b)
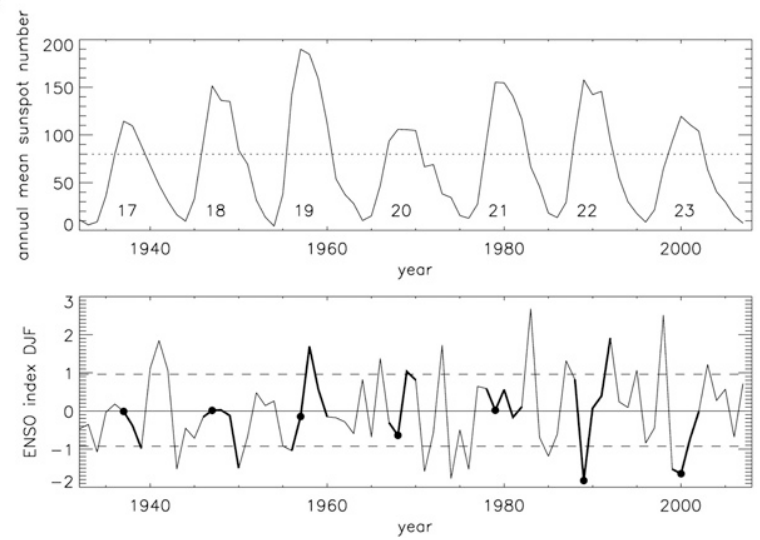

FIG. 2. (a) (top) Annual mean sunspot number during 18561932, with a value of 80 indicated by the horizontal dotted line; numbers indicate solar cycle identity. (bottom) ENSO-3.4 index (DJF) over the same period; dots indicate the peak year of the sunspot cycles, thick lines indicate years for which the sunspot number exceeded 80 , and dashed lines indicate \pm 1 standard deviation from mean value. (b) As in (a), but during 1932-2007.

peak sunspot year. We use January-February data from the Hadley Centre sea level pressure (HadSLP2) dataset because the deep Aleutian low is only present in this season. Figure 1a shows the signal deduced by differencing data from the 11 peak sunspot years of solar cycles 12-22 (see Fig. 2 for solar cycle dates) with those of the 195079 climatology, as carried out by van Loon et al. (2007). A comparison with that paper shows a similar strong positive signal in the region of the Aleutian low, a weak negative region in the North Pacific subtropics, a positive region south of the equatorial Pacific, and a negative region around $70-80^{\circ} \mathrm{N}, 70-100^{\circ} \mathrm{W}$. The van Loon et al. (2007) signals are all larger in magnitude, which may be due to their use of an older dataset (HadSLP1) but perhaps more likely to a seasonal anomaly introduced by using JF for peak years but DJF for the climatology.

Figure $1 \mathrm{~b}$ uses the same solar cycle peak years but a climatology during 1871-1998, as Meehl et al. (2008).
The strong signal in the North Pacific is still present but use of this longer-period climatology results in weaker signals in almost all other regions, except perhaps in the tropical western Pacific, particularly near the western end of the Southern Oscillation seesaw. High-latitude signals in Fig. 1a, particularly the negative patch over Greenland and northeastern Canada identified by van Loon et al. (2007), are significantly weaker.

Figure 1c presents an analysis with the same peak years but a climatology during 1968-96, while Fig. 1d uses this recent climatology with the peaks of the 10 most recent solar cycles, as employed by van Loon and Meehl (2011). It is clear that both restricting the climatology to more recent years and using more recent solar cycle peaks have produced a signal in southern midlatitudes, particularly a positive anomaly around $60^{\circ} \mathrm{S}$, $120^{\circ} \mathrm{W}$, which is not evidenced in the analysis of the earlier/longer datasets. The small dipole signal in the tropics, identified by van Loon et al. (2007) as important in driving the apparent solar influence, has also shifted and changed in strength.

Our results indicate that signals detected by the method of compositing are very sensitive to details of the compositing. It is important that this is recognized so that theories proposed to explain any solar signal in SLP, or climate more generally, are based on robust evidence.

\section{Solar signals and ENSO: Issues of timing}

To address the issue of the timing of cold and warm anomalies in tropical SSTs relative to the phase of the solar cycle, as discussed in section 1, we present in Fig. 2 the time series of the ENSO index during 1856-2007 with the record of the annual mean SSNs over the same period. We use the ENSO-3.4 index for DJF as a measure of SST. Whether a low value of this parameter represents a "true" La Niña event or a solar-induced "La Niña-like" event is immaterial in this context: it just gives a measure of SSTs in the Pacific Ocean in the $\left(5^{\circ} \mathrm{S}-5^{\circ} \mathrm{N}, 120^{\circ}-170^{\circ} \mathrm{W}\right)$ region. The 11-yr cycle in SSNs is clear in Fig. 2; a value of 80 is identified by a horizontal dotted line as an arbitrary choice of a threshold to identify high solar activity. The year of peak SSN in each cycle is identified in the ENSO index record by a filled circle; years for which the SSN exceeds 80 are identified in the ENSO record by a thick line. Some of the data are also presented in an alternative way in Table 1 that identifies the state of ENSO at the solar peak year and for the two subsequent years.

Of the 14 cycles, nine peak sunspot years are associated with a negative ENSO index (i.e., cold tropical SSTs), although in only four of these do the values exceed one standard deviation $\sigma$ from the mean. Only two cycle peaks have positive ENSO index (only one at $>1 \sigma$ ). 
TABLE 1. The state of ENSO (DJF) at the year of peak sunspot number, and the following two years, for the 14 solar cycles during 1856-2007. The letters $\mathrm{C}$ and $\mathrm{W}$ indicate that the ENSO-3.4 index is 0.02 units lower or higher, respectively, than its average value, while a dash indicates a near-neutral state. The horizontal lines between solar cycles 18 and 19 and between solar cycles 22 and 23 indicate the period of intensified meridional overturning circulation.

\begin{tabular}{|c|c|c|c|c|c|}
\hline \multirow[b]{2}{*}{$\begin{array}{c}\text { Solar cycle } \\
\text { number }\end{array}$} & \multirow[b]{2}{*}{ Years } & \multirow[b]{2}{*}{$\begin{array}{l}\text { Peak } \\
\text { year }\end{array}$} & \multicolumn{3}{|c|}{ State of ENSO (DJF) } \\
\hline & & & $\begin{array}{l}\text { Peak } \\
\text { year }\end{array}$ & $\begin{array}{l}1 \text { year after } \\
\text { peak year }\end{array}$ & $\begin{array}{l}2 \text { years after } \\
\text { peak year }\end{array}$ \\
\hline 10 & $1856-67$ & 1860 & $\mathrm{C}$ & $\mathrm{C}$ & $\mathrm{C}$ \\
\hline 11 & $1867-78$ & 1870 & $\mathrm{C}$ & $\mathrm{C}$ & $\mathrm{C}$ \\
\hline 12 & 1878-90 & 1883 & $\mathrm{C}$ & - & W \\
\hline 13 & 1890-1901 & 1893 & $\mathrm{C}$ & $\mathrm{C}$ & $\mathrm{C}$ \\
\hline 14 & $1901-13$ & 1905 & $\mathrm{~W}$ & $\mathrm{~W}$ & $\mathrm{C}$ \\
\hline 15 & $1913-23$ & 1917 & $\mathrm{C}$ & $\mathrm{C}$ & $\mathrm{W}$ \\
\hline 16 & $1923-33$ & 1928 & W & $\mathrm{C}$ & W \\
\hline 17 & $1934-44$ & 1937 & - & $\mathrm{C}$ & $\mathrm{C}$ \\
\hline 18 & $1944-54$ & 1947 & - & $\mathrm{W}$ & $\mathrm{C}$ \\
\hline 19 & $1955-64$ & 1957 & $\mathrm{C}$ & $\mathrm{W}$ & W \\
\hline 20 & $1964-76$ & 1968 & $\mathrm{C}$ & $\mathrm{W}$ & $\mathrm{W}$ \\
\hline 21 & 1976-86 & 1979 & - & W & $\mathrm{C}$ \\
\hline 22 & 1986-96 & 1989 & $\mathrm{C}$ & $\mathrm{W}$ & W \\
\hline 23 & 1996-2007 & 2000 & $\mathrm{C}$ & $\mathrm{C}$ & $\mathrm{C}$ \\
\hline \multirow{3}{*}{\multicolumn{2}{|c|}{ Total }} & $\mathrm{C}$ & 9 & 7 & 8 \\
\hline & & - & 3 & 1 & 0 \\
\hline & & W & 2 & 6 & 6 \\
\hline
\end{tabular}

Earlier than 1957 all years (not just solar peak years) with $\mathrm{SSN}>80$ have negative ENSO indexes, suggesting an overall cold response in tropical eastern Pacific SSTs to solar activity. After that date, while all solar peak years are cold, the overall picture with regard to high SSN years is not so clear.

Meehl et al. (2008) suggested that the cold signal at peak sunspot year is typically followed after 2-3 yr by a warm signal brought about by the same ocean feedbacks that contribute to the development of ENSO. Of the nine cycles identified as cold at the peak sunspot year, four remain cold for the following $2 \mathrm{yr}$ and five become warm after 1 or $2 \mathrm{yr}$. Of the $3 \mathrm{yr}$ initially in the near-neutral state, two subsequently become colder. Thus only 5 of the 14 cycles present the "lagged warm event" of Meehl et al. (2008). Three of these, however, occurred in the most recent five solar cycles so that analyses based on the later period will be more influenced by this apparent response. The analysis of White and Liu (2008), using data from cycles 14-22 inclusive, happens to include four of the five "lagged warm response" cases and to exclude all four cases that remain cold.

Thus, our analysis is not able to confirm the conclusions of Meehl et al. (2009) or those of White and Liu (2008) concerning the evolution of tropical sea surface temperatures following the peak sunspot year. We note, however, that the cycles that do show the cold-to-warm evolution are largely confined to the latter half of the twentieth century, and another possibility is that the solar influence has changed during the 152-yr period.

\section{Solar signal and "climate change"}

The strength of shallow overturning circulation of the tropical Pacific (McPhaden and Zhang 2002), and of the tropical atmospheric Walker circulation (Vecchi et al. 2006; Zhang and Song 2006), declined through the 1950s to 1997 . The overturning circulation has, however, started to recover since 1998 (McPhaden and Zhang 2004). The state of ENSO is closely linked to the Walker circulation so it may be pertinent to ask: if there is a relationship between the solar cycle and ENSO-like behavior, could it be influenced by these apparent shifts in climate?

Figure 3 presents scatterplots of the value of ENSO DJF against annual mean SSN with the year of peak SSN for each solar cycle identified by a square surrounding the symbol. Figure 3a presents the data during 1856-1957 and Fig. 3b during 1958-97, chosen to represent periods of relatively stronger and weaker overturning circulation.

During the earlier period there are no occurrences of a year with high SSN (at the peak of the cycle or otherwise) also having a positive ENSO index. To test the statistical likelihood of this happening by chance a Monte Carlo test was carried out as follows: First, the autoregression coefficients of the ENSO index time series were calculated. Second, one million pseudo-ENSO time series, with the same autoregression characteristics as the original were produced using an autoregressive lag-1 [AR(1)] model [tests using AR orders of up to 11 (not shown) produced no significant difference in the results]. Finally, each pseudo-ENSO series was paired with the SSN time series and the number of occasions when a year had both SSN greater than 80 and ENSO index greater than 0 was noted. Of the one million 100-yr cases only about 200 had no entries in that quadrant, from which we deduce that the probability of the distribution shown in the figure having occurred by chance is about $0.02 \%$. We therefore conclude that over the period 1856-1955 higher levels of solar activity, whether or not the peak SSN years, were associated with a cooling of the tropical eastern Pacific Ocean.

During the later period there is no significant correlation between SSN and ENSO index with more high solar activity (HS) years on the warm side, although, as noted by Roy and Haigh (2010), the peak SSN years appear cold. The difference between the two periods is also implied by the results of Roy and Haigh (2010), whose multiple regression analysis showed very little signal in SST for the whole period 1850-2004 but a slight warming associated with higher solar activity for the latter half of the twentieth century. 


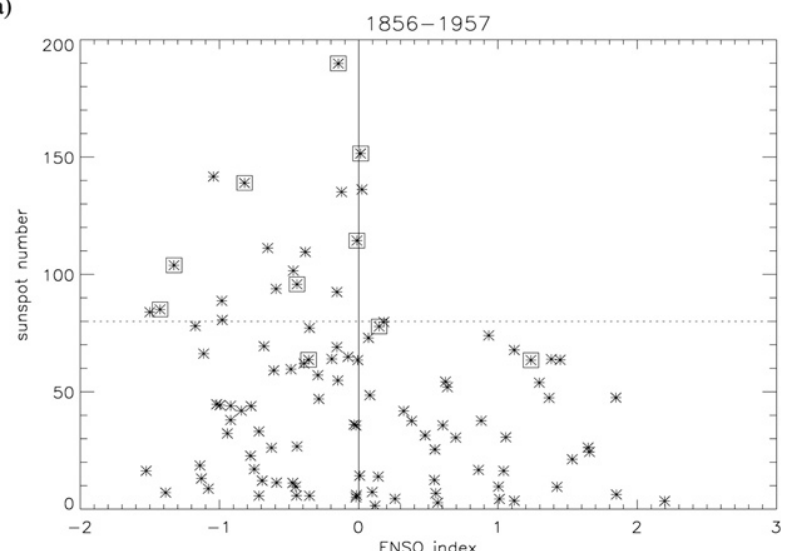

b)

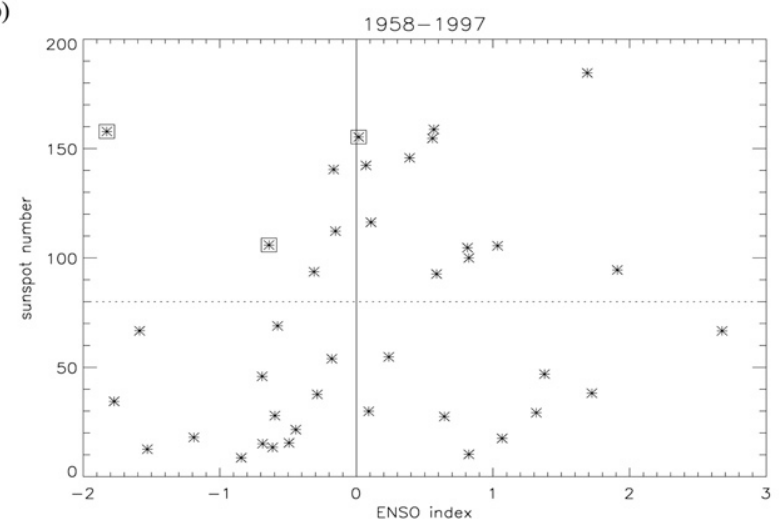

FIG. 3. Scatterplot of DJF mean ENSO index vs annual mean sunspot number during (a) 1856-1957 and (b) 1958-97. A symbol surrounded by a square indicates the peak year of a solar cycle.

Over the last solar cycle (cycle 23, 1996-2007; not included in Fig. 3) ENSO remained cold, more similar to the behavior during 1856-1957. Interestingly, since 1998 the strength of the shallow meridional overturning circulation has rebounded (McPhaden and Zhang 2004) so that both ocean and solar behavior is more similar to the earlier period (1856-1957).

To investigate whether the solar cycle signal in SLP may also have changed during the latter part of the twentieth century, the multiple regression analysis of Roy and Haigh (2010) has been repeated over the two different periods of Fig. 3 [i.e., 1856-1957 (see Fig. 4a) and 1958-97 (Fig. 4b)]. In the earlier period, the positive anomaly in the North Pacific is strong and accompanied by a weaker, but significant, reduction in SLP across the eastern tropical Pacific. In the latter period, however, the positive anomaly in midlatitudes is weaker and the pattern of response over the globe quite unlike that of the earlier period, with no significant signal around the tropics.

If the pattern shown in Fig. 4a is a true solar cycle signal, it raises the question of how it is brought about. There are (at least) three mechanisms proposed specifically relating (a)

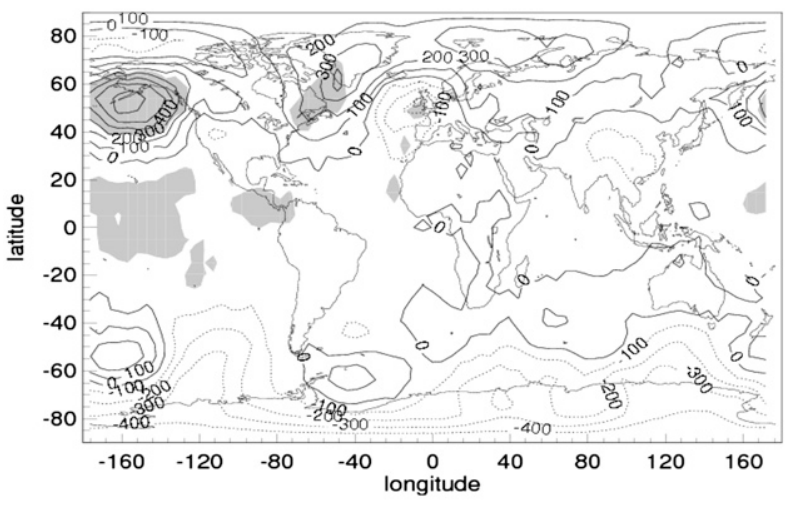

(b)

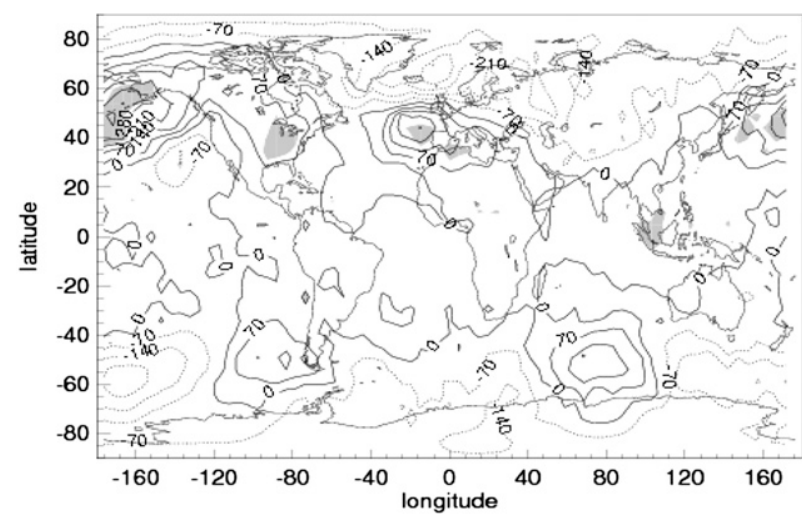

FIG. 4. Amplitude of the component of variability of DJF sea level pressure $(\mathrm{Pa})$ due to solar variability (SSN) deduced using a multiple linear regression analysis of HadSLP2 data for (a) 1856 1957 and (b) 1958-97. Other independent parameters included in the analysis were a linear trend, stratospheric aerosol optical depth, and ENSO index. The values indicate the difference in pressure that the regression coefficient would imply between the years of highest and lowest sunspot number over the period analyzed. Shaded regions are significant at the $95 \%$ level.

to solar forcing: (i) increased solar heating in cloud-free regions of the Pacific produces a La Niña-like response in SSTs and thus an easterly wind stress anomaly in the tropics, which influences the Walker circulation, shifts the ITCZ, and produces wind stress anomalies in the subtropics (Meehl et al. (2008); (ii) solar-induced changes in the stratospheric Brewer-Dobson circulation warm the tropical lower stratosphere and suppress convective activity, especially over the Maritime Continent, which affects the Walker circulation in a fashion dependent on the position of its downward branch, which is a function of the phase of ENSO (Kodera et al. 2007); and (iii) warming of the stratosphere produces changes in the momentum deposition by midlatitude eddies and, through a dynamical coupling with the Hadley circulations, induces poleward shifts in the 
midlatitude jets and low pressure systems (Simpson et al. 2009) and the trade winds.

The results of our work presented here are not sufficient to confirm or deny any of these mechanisms. The signal around the eastern tropical Pacific as seen in Fig. 4a might be associated with an intensification of the ITCZ, uplifting the thermocline and strengthening the Walker circulation. Clement et al. (1996), using a simplified climate model, show how ocean-atmosphere coupling produces a cooling in annual mean SSTs of the eastern Pacific in response to a uniform surface heating and it is plausible that this could be produced by solar heating. The modeling study of Lee et al. (2009) found an increase in the strength of the Walker circulation and intensification of ITCZ in Pacific during HS years but the prime driver remains unclear.

During the latter half of the twentieth century the relationship between cold tropical SSTs and solar activity broke down, but during that period, as shown in Fig. 2, ENSO activity was much stronger than during the previous $100 \mathrm{yr}$; we suggest that the small solar influence has been masked by this much larger effect.

\section{Summary}

Using composites of SLP data from January-February in solar cycle peak years we confirm the strong positive signal in the region of the Aleutian low found by previous authors but we find that signals in other regions of the globe, particularly in the South Pacific, are very sensitive to the choice of reference climatology (see Fig. 1).

We find a marked overall association of higher solar activity with colder temperatures in the eastern tropical Pacific, although this weakened considerably during the period spanning the mid-1950s to 1997 (see Figs. 2 and 3) The SLP signal in the midlatitudes of the North Pacific is consistent with that found at peak solar cycle years by Christoforou and Hameed (1997), van Loon et al. (2007), and Meehl et al. (2008) but is also weaker during the latter period (Fig. 4).

We find no consistent ENSO-like variation in tropical SSTs following peak years of the sunspot cycle as suggested by some previous authors. Such apparent behavior occurs during only 5 of the 14 solar cycles in the available data and mainly during a period when ENSO activity was considerable higher (see Table 1).

Our work suggests that during the period 1958-97 the solar effect was masked by a more dominant ENSO variability, but during the previous century the more subtle solar influence was better able to manifest itself.

Acknowledgments. Indrani Roy was sponsored by a UK Natural Environment Research Council (NERC) postgraduate studentship and by the NERC SOLCLI consortium. We are grateful to Daíthí Stone for providing the Monte Carlo code.

\section{REFERENCES}

Christoforou, P., and S. Hameed, 1997: Solar cycle and the Pacific “centers of action." Geophys. Res. Lett., 24, 293-296.

Clement, A. C., R. Seager, M. A. Cane, and S. E. Zebiak, 1996: An ocean dynamical thermostat. J. Climate, 9, 2190-2196.

Kodera, K., K. Coughlin, and O. Arakawa, 2007: Possible modulation of the connection between the Pacific and Indian Ocean variability by the solar cycle. Geophys. Res. Lett., 34, L03710, doi:10.1029/2006GL027827.

Lee, J. N., D. T. Shindell, and S. Hameed, 2009: The influence of solar forcing on tropical circulation. J. Climate, 22, 5870-5885.

McPhaden, M. J., and D. X. Zhang, 2002: Slowdown of the meridional overturning circulation in the upper Pacific Ocean. Nature, 415, 603-608. , and - 2004: Pacific Ocean circulation rebounds. Geophys. Res. Lett., 31, L18301, doi:10.1029/2004g1020727.

Meehl, G. A., and J. M. Arblaster, 2009: A lagged warm event-like response to peaks in solar forcing in the Pacific region. J. Climate, 22, 3647-3660.

, - _ , G. Branstator, and H. van Loon, 2008: A coupled airsea response mechanism to solar forcing in the Pacific region. J. Climate, 21, 2883-2897.

, _ _ K. Matthes, F. Sassi, and H. van Loon, 2009: Amplifying the Pacific climate system response to a small 11-year solar cycle forcing. Science, 325, 1114-1118.

Roy, I., and J. D. Haigh, 2010: Solar cycle signals in sea level pressure and sea surface temperature. Atmos. Chem. Phys., 10,3147-3153.

Simpson, I. R., M. Blackburn, and J. D. Haigh, 2009: The role of eddies in driving the tropospheric response to stratospheric heating perturbations. J. Atmos. Sci., 66, 1347-1365.

Tung, K. K., and J. S. Zhou, 2010: The Pacific's response to surface heating in $130 \mathrm{yr}$ of SST: La Niña-like or El Niño-like? J. Atmos. Sci., 67, 2649-2657.

van Loon, H., and G. A. Meehl, 2008: The response in the Pacific to the sun's decadal peaks and contrasts to cold events in the Southern Oscillation. J. Atmos. Sol.-Terr. Phys., 70, 1046-1055, doi:10.1016/j.jastp.2008.01.009.

- and _ 2011: The average influence of decadal solar forcing on the atmosphere in the South Pacific region. Geophys. Res. Lett., 38, L12804, doi:10.1029/2011GL047794.

$\longrightarrow,-$, and D. J. Shea, 2007: Coupled air-sea response to solar forcing in the Pacific region during northern winter. J. Geophys. Res., 112, D02108, doi:10.1029/2006JD007378.

Vecchi, G. A., B. J. Soden, A. T. Wittenberg, I. M. Held, A. Leetmaa, and M. J. Harrison, 2006: Weakening of tropical Pacific atmospheric circulation due to anthropogenic forcing. Nature, 441, 73-76, doi:10.1038/nature04744.

White, W. B., and Z. Y. Liu, 2008: Non-linear alignment of El Niño to the 11-yr solar cycle. Geophys. Res. Lett., 35, L19607, doi:10.1029/2008gl034831.

, J. Lean, D. R. Cayan, and M. D. Dettinger, 1997: Response of global upper ocean temperature to changing solar irradiance. J. Geophys. Res., 102, 3255-3266.

Zhang, M. H., and H. Song, 2006: Evidence of deceleration of atmospheric vertical overturning circulation over the tropical Pacific. Geophys. Res. Lett., 33, L12701, doi:10.1029/2006g1025942.

Zhou, J. S., and K. K. Tung, 2010: Solar cycles in 150 years of global sea surface temperature data. J. Climate, 23, 3234-3248. 